УДК: $65.0(075.32)$

$10.17213 / 2075-2067-2020-5-247-255$

\title{
СОЦИОКУЛЬТУРНЫЕ ОСНОВАНИЯ УПРАВЛЕНИЯ ПЕРСОНАЛОМ В СОВРЕМЕННОЙ РОССИИ
}

\author{
(C) 2020 г. М. Т. Белов, А. В. Волочай, С. И. Самыгин
}

\section{Ростовский государственный экономический университет (РИНХ), 2. Ростов-на-Дону, Россия}

Цель исследования. В данной статье исследуются соииокультурные основания управления персоналом в современном российском обществе.

Методология исследования основывается на концепциях организационной культуры и культурологическом подходе к анализу социальных явлений и процессов в цеелом и процесса управления персоналом в частности.

Результаты исследования. Культура представляет собой совокупность идей, представлений и норм, определяющих поведение человека. Культура народа - результат длительного исторического развития. Культура общества оказывает определяющее воздействие на такой ее сегмент, как организачионная культура, включающая и определеннье модели управления персоналом. Специфика управления персоналом в современном российском обществе определяется культурным наследием советского общества, которое, в свою очередь, вобрало в себя более ранние установки и практики. В статье выделяются специфические черты, свойственные российскому управлению персоналом.

Перспективы использования результатов исследования. Результаты исследования могут использоваться в дальнейшем культурологическом и сочиологическом анализе проблем управления, а также в управленческой практике.

Ключевые слова: управление персоналом; культура; организационная культура; модернизация; менеджмент.

\section{SOCIO-CULTURAL FOUNDATIONS OF PERSONNEL MANAGEMENT IN MODERN RUSSIA}

\section{(C) 2020 M. T. Belov, A. V. Volochay, S. I. Samygin}

\section{Rostov State University of Economics (RSUE), Rostov-on-Don, Russia}

Purpose of research. This article investigates the sociocultural foundations of HR management in modern Russian society.

The research methodology is based on the concepts of organisational culture and a cultural approach to analysing social phenomena and processes in general and the HR management process in particular.

Research result. Culture is a set of ideas, perceptions and norms that define human behaviour. The culture of the people is the result of long historical development. The culture of society has a decisive influence on its segment, such as organisational culture, which also includes certain models of personnel management. The specifics of HR management in modern Russian society are determined by the cultural heritage of Soviet society, which, in turn, has 
incorporated earlier attitudes and practices. The article highlights the specific features of Russian HR management.

Prospects for using the research results. The results can be used for further cultural and sociological analysis of management problems, as well as in management practice.

Key words: personnel management; culture; organizational culture; modernization; management.

Введение. Культура - одно из самых многозначных понятий, используемых в научном дискурсе. Это неудивительно, поскольку именно культура представляет собой специфику человеческого существования и человеческой деятельности, при этом значение культурного фактора в управлении организациями и управлении персоналом было осознано теоретиками и практиками менеджмента относительно недавно. Это осознание выразилось в возникновении понятия «организационная культура» и формировании различных подходов к ее изучению. В данной статье речь пойдет о соотношении организационной культуры и культуры как среды деятельности организации. Культурный фактор имеет прямое отношение к методам управления персоналом.

Теоретический аспект. В отличие от животных, человек лишен генетически наследуемых программ поведения. Это свойство, которое делает человека более уязвимым перед природой, в то же время обеспечило ему свободу выбора поведенческих стратегий. Культура как коллективный опыт, передаваемый в ходе социализации и обучения от поколения к поколению [1], заменила человеку недостающие инстинкты. Культура представляет собой совокупность идей, образов, символов и программ поведения, которые определяют цели и формы деятельности человека во всех сферах его существования. Таким образом, культура представляет собой не теоретическую абстракцию, но способ самого человеческого бытия [2].

Поскольку человек свободен от диктата инстинктов, его поведение гораздо вариативнее поведения самого сложноорганизованного животного. Человек сумел освоить разнообразные экологические ниши от тропиков до арктических ландшафтов. Это было первичным фактором, определяющим спе- цифику той или иной культуры. Не существует универсальной культуры, разные человеческие группы создавали в ходе своего существования различные формы культурных миров. Взаимодействие между разными культурами могло иметь разные последствия: от взаимообогащения культур за счет обмена культурными достижениями до уничтожения одной культуры другой. Уничтожение необязательно подразумевало физическую гибель ее носителей, но могло принимать форму аккультурации и ассимиляции - растворения одной культуры в пространстве другой.

По мере развития и усложнения человеческих сообществ их культура становилась все более многообразной, в ней выделялись отдельные сегменты, связанные с разными видами деятельности - от искусства до политики и экономики. В рамках отдельных сегментов деятельности формировались определенные стандарты поведения, особые цели и ценности. Культура - это не только совокупность поведенческих программ, но также и различные смысловые конструкции, которые определяют предпочтение тех или иных форм поведения. Бергер и Лукман называют такие конструкции «смысловыми универсумами», которые объясняют и в то же время легитимируют принятые поведенческие стандарты в рамках группы или общества [3].

Культура того или иного народа формируется на протяжении столетий, поэтому она представляет собой инерционный феномен. В то же время любая культура меняется под воздействием различных факторов природного или исторического характера. Темпы изменения могут быть различными, если они постепенны и происходят на протяжении жизни нескольких поколений, то носители культуры вообще могут их не замечать, такие изменения не подразумевают каких-то резких разрывов с устоявшимися нормами и представлениями. Но изменения могут 
быть и очень быстрыми. В этом случае могут возникать проблемы адаптации к новым условиям, сопровождающиеся социокультурным кризисом [4], аномией - ситуацией, когда нормы и ценности противоречат друг другу и человек оказывается дезориентированным в своем поведении [5].

Формирование обществ современного типа было результатом постепенного накопления изменений в рамках европейских культур, в определенный исторический момент количество перешло в качество: возник особый тип общества, который впервые в истории подразумевал ориентацию не на воспроизводство традиционных культурных образцов, а на систематическое производство инноваций в самых разных сферах. Еще одной специфической чертой общества современного типа стало осознанное и целенаправленное воздействие на социальные процессы, в основе которого лежало знание. На рубеже XIX-XX веков в западных обществах начинает формироваться теоретический менеджмент, который подразумевает выработку моделей эффективного управления людьми, включенных в деятельность различного рода организаций [6].

Культурные факторы управления. Важность культурного фактора для управления организациями была осознана не сразу. В США и других западных обществах это произошло в 70-80-е гг. XX века, в нашей стране - после распада СССР и формирования в постсоветском обществе новой системы отношений в рамках организаций, существовавших теперь не в социалистическом, а в формирующемся катастрофически быстрыми темпами капиталистическом обществе. Новые формы управления и в хозяйственной, и в политической сферах еще не сложились. В связи с этим управленческая деятельность носила авральный и реактивный характер (реактивный в том смысле, что управленческие решения и стратегии часто определялись ситуативными вызовами со стороны внешней среды организации, были реакцией на эти вызовы). В этой ситуации оказались очень востребованными западные теории и практики менеджмента, постепенно росло осознание значимости культурного фактора в управлении персоналом [7].
Теоретический анализ роли культуры в управлении персоналом в США был обусловлен не только накоплением знаний об управлении в рамках западных обществ, но и внешним фактором - неожиданно быстрым ростом японской экономики в 70-80-е гг. прошлого века. Этот успех был во многом обусловлен особым типом управления японских корпораций, который базировался на японской культурной традиции, очень отличавшейся от западной.

Японский тип управления персоналом в рамках корпораций базировался на принципах, практически противоположных западной модели. Он подразумевал специфическое сочетание огромного почтения к менеджменту корпораций с высокой степенью включенности персонала в деятельность корпорации, восприятие корпорации как большой семьи, в благе которой заинтересованы все, но управляющие несут большую ответственность за результат, чем подчиненные. В японских корпорациях от работников любого уровня требуется готовность усердно работать, превышая установленные нормы, поддерживать общий дух корпорации, участвовать не только в труде, но и в общих ритуалах корпорации, чувствовать свою ответственность не только перед начальством, но и перед сослуживцами [8].

В японских корпорациях большую роль играла именно коллективная ответственность, когда работник отвечал за группу, но и группа отвечала за работника. Это групповое воздействие делало ненужным вмешательство вышестоящих в управление качеством труда, работники сами стремились контролировать его и воздействовать на тех, кто по какой-то причине работал плохо. Кроме того, японские корпорации практиковали пожизненный найм работников, успешно прошедших испытательный срок. Это мотивировало людей на полную отдачу всех сил корпорации. Коллективизм, круговая порука, иерархизм, пожизненный найм - все это противоречило принятым в западном обществе моделям управления, которые подчеркивали значимость не сотрудничества, а конкуренции между работниками, поощряли их желание выдвинуться, «показать себя». В то же время западный работник никогда не стал бы добровольно перерабатывать сверх установленных норм, он не отождествляет своих личных интересов с организаци- 
ей. Все это связано с западной культурой индивидуализма и духом соперничества. В такой культурной среде попытки воспроизводить японские практики выглядели бы фальшиво и не дали бы заметного улучшения. Однако необходимость учитывать мотивацию работников, необходимость формирования солидарности, в основе которой лежит общий дух, общие цели и ценности, повлияли на формирование моделей управления персоналом в западных организациях.

Сравнение западного и японского типа управления организациями и персоналом показало, что управление не единообразно, разные типы управления могут вести к эффективности или, наоборот, ей препятствовать. Попытки перенести японскую модель управления в западные организации были не слишком успешны, поскольку в западных обществах японские методы выглядели чужеродными, они не подходили людям с западным менталитетом. Попытки внедрять японские методы наблюдались и в постсоветской России, но и здесь они не прижились, как не слишком успешно приживались в России и западные модели управления организационной культурой и персоналом.

Любая организация находится в определенном культурном окружении. Каждый работник, нанимаемый организацией, представляет собой не чистый лист, на котором можно писать что угодно, но личность с определенным культурным опытом или, говоря словами П. Бурдье, с определенным габитусом [9], потому задача управления состоит в том, чтобы организовать эффективное управление персоналом, опирающееся не только на нормы отдельной корпоративной культуры, но и на нормы культуры, доминирующие в социуме в целом. Иными словами, культура организации должна соответствовать культуре общества, если это возможно. Проблема состоит в том, что довольно часто доминирующие в обществе культурные нормы и ценности могут противоречить тем требованиям, которые организация предъявляет работникам. Успех японских корпораций был обусловлен удачным сочетанием западной модели капиталистического производства и сохранившегося в Японии общинного духа [10]. Но синтез своих и чужих культурных моделей не всегда бывает удачным.
Культурная специфика управления

в России. На формирование управленческих моделей в российском обществе огромное влияние оказывал советский опыт, избавиться от которого оказалось сложнее, чем от руководящей и направляющей роли КПСС. Специфика этого опыта состоит в том, что он сочетает авторитаризм и бюрократизм, а также отсутствие инициативы у большинства работников - только в российской среде могла сформироваться поговорка «инициатива наказуема». Такая установка отличается и от западной, и от японской «модели» работника. В западной культуре работник должен быть нацелен на активность и инициативу, это дает преимущество в конкуренции с другими работниками. В японской модели работник отождествляет себя с коллективом и работает не только ради собственной карьеры, но и для коллектива, его мотивация достаточна высока. Российский работник отличается от этих моделей. Он нацелен только на выполнение собственной задачи с наименьшими усилиями и отчужден как от руководства, так и от коллектива. «Коллективизм», нередко приписываемый российским работникам, на деле - всего лишь отсутствие личной инициативы в условиях неопределенности ее результатов. Для российских работников характерен не столько коллективизм как солидарность, сколько коллективизм как круговая порука. Это связано с незащищенностью работника от произвола руководства, порождающей спонтанные практики ускользания от ответственности. Коллектив по мере сил «прикрывает» нарушителя, поскольку в следующий раз может потребоваться прикрыть любого другого. Карьера работника в российских условиях отнюдь не всегда связана с адекватной оценкой качества его труда руководством, потому нет резона доказывать свои профессиональные качества сверх необходимого минимума. «Незаменимых нет» еще одна культурная установка, влияющая негативно на мотивацию российского персонала и российских руководителей.

Как отмечает А.П. Прохоров [11], для отечественной модели управления персоналом характерны следующие особенности:

- низкое значение конкуренции, причем как внутри организаций, так зачастую и между ними. Проблема в том, что в Рос- 
сии не сложилась полноценная рыночная среда. Преимущество в конкуренции часто дают не индивидуальные достижения (в случае работника) и не высокая эффективность (в случае организации), а такие факторы, как, например, умение использовать административный ресурс и «договариваться»;

- высокая степень централизации управления. Это традиционный российский бюрократизм в разных его проявлениях. В российском управлении почти не практикуется делегирование полномочий или учет мнения работников. От работников, как правило, не требуют инициативы, напротив, инициатива часто карается. Это определяет и формы управления персоналом;

- маятниковый режим трудовой активности. Ситуации повышения активности (знаменитый российский «аврал») чередуются с периодами спокойствия и почти застоя. Как отмечают многие исследователи, эта черта имеет глубокие исторические корни в особенностях крестьянского труда в России с ее климатическими условиями. В советский период эта черта вновь проявилась в связи с необходимостью наверстывать «план» в сжатые сроки;

- уравнительность. В рамках российской культуры, в том числе и хозяйственной, высока ценность равенства и, наоборот, неприязнь к «выскочкам». В современных условиях эта черта способна ограничивать инициативу работника, которому «больше всех надо»;

- двойственность существующих норм, преобладание неформальных отношений над формальными. В теоретическом менеджменте проблема сочетания неформального и формального аспекта организационной структуры известна давно, эта черта присуща всем организациям. Но в российских условиях преобладание неформальной стороны взаимодействия в рамках организации имеет особенно большое значение. Продвижение сотрудников, их найм и увольнение чаще зависят от неформальных отношений, чем от формальных показателей эффективности труда и формальных правил. Это связано с укорененной в российской культуре неприязнью к «формальным нормам», важной ролью «знакомств» и «блата» в трудоустройстве и карьере.
Наследием позднесоветской управленческой культуры является специфическое двоемыслие, ситуация, когда работники различают «официальный дискурс» управленцев (имеющий ритуальное значение) и «реальную жизнь». В советских условиях формирование данной черты было обусловлено присутствием официальной идеологии, в которую никто всерьез уже не верил. В современных условиях столь же скептически могут восприниматься усилия менеджмента сформировать «корпоративную культуру» в соответствии с западными учебниками [12, $13,14]$. Работники привычно демонстрируют внешнюю лояльность, участвуя в корпоративных мероприятиях, но на самом деле не испытывают ни общности корпоративного духа, ни ответственности за судьбу организации и трудового коллектива [14], причем подобный скепсис имеет вполне реальные причины, ряд из которых мы рассмотрели выше.

Несмотря на отчуждение персонала от руководства организацией, российская организационная культура несет на себе печать патернализма [15]. Работники склонны ожидать от руководства определенных гарантий и «понимания» нужд и потребностей работников. И эти ожидания находятся в резком противоречии с реальностью современной России, когда даже многие государственные и тем более частные организации не желают или не могут брать на себя даже предусмотренные законом социальные обязательства перед работниками [16]. Значительная часть экономической активности находится в сфере неформальной, где отношения между работодателем и наемным работником строятся на неформальных договоренностях, которые допускают определенные взаимные уступки, но не подразумевают практически никаких гарантий для работника. Противоречие между патерналистскими ожиданиями и реальными обстоятельствами усиливает недоверие работников к руководству. Необходимость действовать в ситуации высокой неопределенности и зачастую правовой незащищенности накладывает отпечаток и на менеджмент, и на персонал современных российских организаций, не способствуя эффективности их деятельности.

Заключение. Выделенные в статье характеристики управления в современном рос- 
сийском обществе обусловлены культурными и историческими факторами. Особенное влияние на российские практики управления имеет советский опыт, который, в свою очередь, имел в качестве предпосылки традиции российского управления в целом, специфическую ментальность. Стремясь усовершенствовать управление персоналом сегодня, необходимо осознавать, что принятие любых моделей управления, сформированных в других культурных контекстах, должно опираться на понимание культурных особенностей российского общества.

\section{Литература}

1. Гафиатулина Н.X. Социальное здоровье и социализация российской студенческой молодежи // Социально-гуманитарные знания. - 2014. - №11. - С. 175-180.

2. Белов М.Т., Гафиатулина Н.Х., Самьгин С.И. Управление религиозными ориентирами в сознании современной молодежи // Экономические проблемы России и региона. Ученые записки. Ростовский государственный экономический университет (РИНХ). Ростов-на-Дону, 2019. - С. 186-193.

3. Алексеев А. С., Пантелеев С. С., Голодаев Д.М., Савина А.О., Крыжевская С.И., Васина A.В. Особенности современного российского стиля управления // Научно-методический электронный журнал «Концепт». 2016. - T. 43. - C. 180-184.

4. Гафиатулина Н.Х., Касьянов В.В., Самылин П. С., Самызин С.И. Российское общество в условиях самоизоляции. Социальные эффекты и последствия пандемии Covid-19. Монография. - Москва, 2020.

5. Гафиатулина Н.Х., Касьянов В.В., Самыгенн С.И. Социальный иммунитет российского общества в условиях угрозы коронавируса: риски социокультурной травматизации// Гуманитарий Юга России. - 2020. T. 9. 一 №2. - С. 147-158.

6. Воденко К.В., Самыгин С.И., Волков Ю. Ю., Иванченко О. С. и др. Экономика и социология труда. - М.: Издательско-торговая корпорация «Дашков и К», 2019. $308 \mathrm{c}$.

7. Десслер Г. Управление персоналом. М.: БИНОМ. Лаборатория знаний, 2004. 799 c.
8. Спивак B.A. Организационное поведение и управление персоналом. - СПб.: Питер, - 2000. - $416 \mathrm{c}$.

9. Руденко А.М., Котлярова В.В., Самызин С.И., Попов А.В., Дорошенко А.Ю., Латышева А.Т. Управление персоналом. Ростов-на-Дону, 2020. - 319 с.

10. Самызин С.И., Колесникова Г.И., Епифанцев С.Н. Социология и психология управления. - М.: Кнорус, 2020. - 254 с.

11. Прохоров А. П. Русская модель управления. - М.: Эксмо, 2009. - 384 с.

12. Бурмистров С.В., Волочай А.В., Самыган С.И. Мотивы трудовой деятельности в системе управления персоналом организации // Гуманитарные, социально-экономические и общественные науки. - 2019. №9. - С. 26-29.

13. Гафиатулина Н.X. Влияние корпоративной культуры вуза на социальное здоровье студенческой молодежи // Образование. Наука. Инновации. — 2012. — №6 (26). C. 113-119.

14. Belov M.T., Vaskov M.A., Vorobyev G.A., Burmistrov S. V., Samygin S. I. Specifics of managerial competencies in the context of managing the personnel of an educational organization / In the book: Public Administration and Regional Management in Russia. Challenges and Prospects in a Multicultural Region. Ser. "Contributions to Economics». - Switzerland, 2020. P. 291-298.

15. Белов М.Т., Рачипа А.В., Самьихи С.И. Факторы стимулирования трудовой мотивации при управлении персоналом организации // Гуманитарные, социально-экономические и общественные науки. - 2019. №9. - С. 15-18.

16. Ахматова А.С., Волочай А. В. Особенности управления персоналом на различных этапах жизненного цикла организации / В сборнике: Модернизация экономики России: отраслевой и региональный аспект. Материалы международной научно-практической конференции профессорско-преподавательского состава, молодых ученых и студентов. - 2016. - С. 242-244.

\section{References}

1. Gafiatulina N.H. Social'noe zdorov'e i socializacija rossijskoj studencheskoj molodezhi 
[Social health and socialization of Russian students] // Social'no-gumanitarnye znanija [Social and humanitarian knowledge]. — 2014. №11. - Pp. 175-180.

2. Belov M.T., Gafiatulina N.H., Samygin S.I. Upravlenie religioznymi orientirami v soznanii sovremennoj molodezhi [Management of religious landmarks in the minds of modern youth]// Jekonomicheskie problemy Rossii i regiona. Uchenye zapiski. Rostovskij gosudarstvennyj jekonomicheskij universitet (RINH) [Economic problems of Russia and the region. Scientific notes. Rostov State University of Economics (RSUE)]. - Rostov-on-Don, 2019. - Pp. 186-193.

3. Alekseev A.S., Panteleev S.S., Golodaev D. M., Savina A.O., Kryzhevskaja S.I., Vasina A.V. Osobennosti sovremennogo rossijskogo stilja upravlenija [Features of modern Russian management style] // Nauchno-metodicheskij jelektronnyj zhurnal «Koncept» [Scientific and methodological electronic journal]. — 2016. — Vol. 43. Pp. 180-184.

4. Gafiatulina N.H., Kas'janov V. V., Samygin P.S., Samygin S.I. Rossijskoe obshhestvo v uslovijah samoizoljacii. Social'nye jeffekty i posledstvija pandemii Covid-19. Monografija [Russian society in the conditions of self-isolation. Social effects and consequences of the Covid-19 pandemic. Monograph]. - Moscow, 2020.

5. Gafiatulina N.H., Kas'janov V. V., Samygin S.I. Social'nyj immunitet rossijskogo obshhestva $\mathrm{v}$ uslovijah ugrozy koronavirusa: riski sociokul'turnoj travmatizacii [The Social immunity of the Russian society in terms of the threat of coronavirus: the risks of social and cultural traumatisation] // Gumanitarij Juga Rossii [Humanities of the South of Russia]. - 2020. Vol. 9. - №2. - Pp. 147-158.

6. Vodenko K.V., Samygin S.I., Volkov Ju. $J u$., Ivanchenko O.S. $i d r$. Jekonomika i sociologija truda [Economics and sociology of labor]. - Moscow: Izdatel'sko-torgovaja korporacija «Dashkov i K», 2019. - 308 p.

7. Dessler G. Upravlenie personalom [Personnel Management]. - Moscow: BINOM. Laboratorija znanij, 2004. - 799 p.

8. Spivak V.A. Organizacionnoe povedenie i upravlenie personalom [Organizational behavior and personnel management]. - Saint-Petersburg: Piter, - 2000. - 416 p.
9. Rudenko A.M., Kotljarova V.V., Samygin S. I., Popov A. V., Doroshenko A. Ju., Latysheva A.T. Upravlenie personalom [Personnel Management]. — Rostov-on-Don, 2020. - 319 p.

10. Samygin S. I., Kolesnikova G.I., Epifancev S.N. Sociologija i psihologija upravlenija [Sociology and psychology of management]. Moscow: Knorus, 2020. - 254 p.

11. Prohorov A. P. Russkaja model' upravlenija [Russian model of management]. - Moscow: Jeksmo, 2009. - 384 p.

12. Burmistrov S.V., VolochajA.V., Samygin S.I. Motivy trudovoj dejatel'nosti v sisteme upravlenija personalom organizacii [Motives of labor activity in the organization's personnel management system] // Gumanitarnye, social'no-jekonomicheskie i obshhestvennye nauki [Humanities, socio-economic and social Sciences]. — 2019. — №9. — Pp. 26-29.

13. Gafiatulina N.H. Vlijanie korporativnoj kul'tury vuza na social'noe zdorov'e studencheskoj molodezhi [Influence of corporate culture of the University on the social health of students] // Obrazovanie. Nauka. Innovacii [Education. The science. Innovation]. — 2012. №6 (26). - Pp. 113-119.

14. Belov M.T., Vaskov M.A., Vorobyev G.A., Burmistrov S.V., Samygin S.I. Specifics of managerial competencies in the context of managing the personnel of an educational organization / In the book: Public Administration and Regional Management in Russia. Challenges and Prospects in a Multicultural Region. Ser. «Contributions to Economics». - Switzerland, 2020. P. 291-298.

15. Belov M.T., Rachipa A.V., Samygin S.I. Faktory stimulirovanija trudovoj motivacii pri upravlenii personalom organizacii [Factors stimulating motivation in managing the organization's staff] // Gumanitarnye, social'no-jekonomicheskie i obshhestvennye nauki [Humanitarian, socio-economic and social Sciences]. 2019. — №9. — Pp. 15-18.

16. Ahmatova A.S., Volochaj A.V. Osobennosti upravlenija personalom na razlichnyh jetapah zhiznennogo cikla organizacii [Peculiarities of personnel management on different stages of the life cycle of the organization] / V sbornike: Modernizacija jekonomiki Rossii: otraslevoj i regional'nyj aspekt. Materialy mezhdunarodnoj nauchno-prakticheskoj konferencii professorsko-prepodavatel'skogo 
sostava, molodyh uchenyh i studentov [In the book: Modernization of the Russian economy: industry and regional aspects. Materials of the international scientific and practical conference of the teaching staff, young scientists and students]. - 2016. - Pp. 242-244.

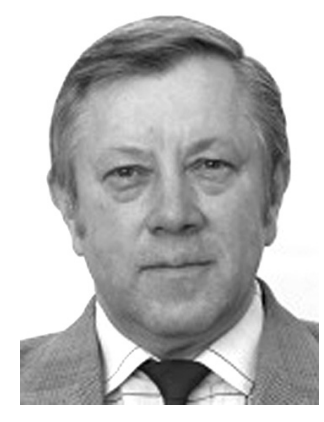

344002, г. Ростов-на-Дону, ул. Большая Садовая, 69

69 Bolshaya Sadovaya st., 344002, Rostov-on-Don, Russia

E-mail: kafedraypis@mail.ru университета (РИНХ). (RSUE).

Белов Михаил Тимофеевич - кандидат социологических наук, доцент, заведующий кафедрой «Управление персоналом и социология〉 Ростовского государственного экономического

Belov Mikhail Timofeevich - Candidate of Sociological Sciences, Associate Professor, Head of the Department of Personnel Management and Sociology, Rostov State University of Economics

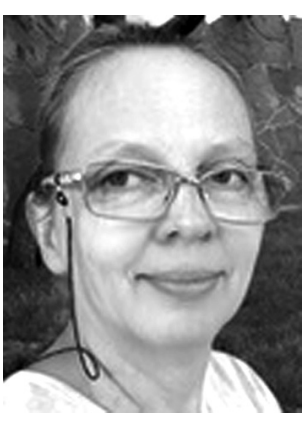

Волочай Анна Владимировна - кандидат философских наук, доцент кафедры «Управление персоналом и социология» Ростовского государственного экономического университета (РИНХ).

Volochay Anna Vladimirovna - Candidate of Philosophical Sciences, Associate Professor, Department of Personnel Management and Sociology, Rostov State University of Economics (RSUE).

344002, г. Ростов-на-Дону, ул. Большая Садовая, 69

69 Bolshaya Sadovaya st., 344002, Rostov-on-Don, Russia

E-mail: anna64.01@eandex.ru 


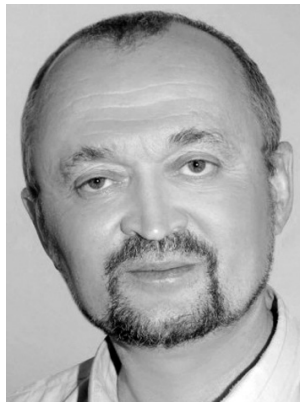

Самыгин Сергей Иванович - профессор, доктор социологических наук, профессор кафедры управления персоналом и социологии Ростовского государственного экономического университета (РИНХ).

Samygin Sergey Ivanovich - Professor, Doctor of Sociological Sciences, Professor, Department of Personnel Management and Sociology, Rostov State University of Economics (RSUE).

344002, г. Ростов-на-Дону, ул. Большая Садовая, 69

69 Bolshaya Sadovaya st., 344002, Rostov-on-Don, Russia

E-mail: darya.maksimovich@gmail.com 